\title{
Adult outcome of children reared for long-term periods in foster families
}

Annick-Camille Dumaret $^{1 *}$, Marthe Coppel-Batsch ${ }^{2}$, Simone Couraud ${ }^{2}$

1 CERMES, Centre de recherche Médecine, Science, Santé et Société CNRS : URA0934, INSERM : U304, 182 Boulevard de la Villette, 75019 Paris, FR

2 Fondation Grancher Fondation Grancher, 119, Rue de Lille, 75007 PARIS, FR

* Correspondence should be adressed to: Annick-Camille Dumaret <dumaret@vjf.cnrs.fr >

\section{Abstract \\ Objective}

To study the long term impact of adverse childhood experiences resulting from family breakdowns combined with a stable care environment. An other aim was to determine predictive factors for maladjusted psycho-social integration in adulthood.

\section{Method}

63 children from severely psychosocially dysfunctioning families selected from among those having been in care in an institutional setting: all had been reared for at least 5 years by foster families, had been out of care for more than 5 years and were at least 23 years old at the time of the survey. Semi-structured interviews were used in a follow-up study to assess adult outcome, essentially in terms of professional status, social and family relationships.

Results

Data was obtained for $94 \%$ of the study population ( $n=59)$, $71 \%$ via direct interviews $(n=45)$. The majority had managed to overcome their childhood adversities: $56 \%$ were well-integrated socially, $12 \%$ had average integration results, $20 \%$ were partially integrated and $10 \%$ were in situations of failure. These difficulties were linked to multiple family disturbances and repeated traumatic experiences during childhood $(\mathbf{p}<.05)$. Multiple regression analyses indicated that these risk factors accounted for $28 \%$ of the variance in the social integration score ( $p<.0001)$. Severe emotional deprivation over a prolonged period was a contributing factor to clinical disorders.

\section{Conclusion}

At the study period, intergenerational repetition of "child placement" behaviors, significant in the previous generation, had practically disappeared. The results also highlighted the substantial psychotherapeutic and child-rearing assistance provided by the staff of the foster care agency.

MESH Keywords Adolescent ; Adult ; Age Factors ; Chi-Square Distribution ; Child ; Child Abuse ; psychology ; statistics \& numerical data ; Child Welfare ; Child of Impaired Parents ; psychology ; statistics \& numerical data ; Family Characteristics ; Family Health ; Female ; Follow-Up Studies ; Foster Home Care ; psychology ; standards ; statistics \& numerical data ; France ; epidemiology ; Health Surveys ; Humans ; Interpersonal Relations ; Male ; Maternal Deprivation ; Mental Disorders ; epidemiology ; Paternal Deprivation ; Prospective Studies ; Regression Analysis ; Retrospective Studies ; Risk Factors ; Social Adjustment ; Treatment Outcome

Author Keywords foster care ; intergenerational continuities ; social integration ; follow-up study

Stimulated by the new ideas on children in care (Soulé \& Noël, 1971 ; Goldstein, Freud and Solnit, 1973 ), caretaking practices have evolved in recent years, essentially in an attempt to lessen the impact of change on the child's life, maintain family contacts and improve the supportive environment within the foster families. The private foster care agency involved in the study, Oeuvre Grancher, has consistently upgraded its practices to keep pace with this trend and its staff now provide backup and therapeutic care for both the children in its care and their families.

More needed to be known about the impact of care on children and adolescents from very deprived families and its outcome. If it is true to say that deprived environments lead to developmental delays, then it should follow that stable foster care in a supportive environment will ensure continuity in a child's relationships and facilitate his eventual integation into the social structure. However, the influence of intergenerational transmission of psychosocial problems must still be accounted for.

Our research aimed to measure the effects of adverse childhood experiences after a family breakup which were followed by a period of stability in a care environment. A second objective was to determine the extent to which family hardship and maladjusted behavior are transmitted from one generation to the next.

\section{INTRODUCTION}

The long-term effects of both maternal and relationship deprivation have not been examined to the same extent as their short term effects (Clarke \& Clarke, 1976 ). Most studies dealing with children and adolescents in care have highlighted substantial developmental 
deficiencies and health problems, in addition to cognitive, emotional and behavioral disturbances (Pringle \& Bossio, 1971 ; Wolkind \& Rutter, 1973 ; Swire \& Kavaler, 1977 ). However, findings are difficult to compare due to a lack of commonalities in the populations studied, not only in terms of their legal status (wards of state, children in temporary care, children committed by courts) and the type of foster care (foster or adoptive families, residential institutions) but also in terms of the length of separation from the family and the time spent in care (Ainsworth, 1962 ; Klee \& Halfon, 1987 ; Dumaret, 1988a ). The impact of deprivation and ill-treatment depends to a large extent on whether or not they are repeated and prolonged during childhood and adolescence (Rutter \& Madge, 1976 ; Essen \& Wedge, 1982 ). Research on children who have experienced a significant upheaval in their social circumstances such as adoption (Triseliotis, 1980 ; Duyme \& Dumaret, 1990 ) or long-term care in foster families (Fanshel \& Shinn, 1978 ; Rowe, Cain, Hundleby and Keane, 1984 ; Dumaret, 1988b ; Dumaret \& Stewart, 1989 ; Aldgate, Colton, Gathe and Health, 1992 ) has highlighted the positive effects of such changes in environment, both in terms of cognitive development and adjustment in school. However, such adaptation depends on factors specific to each individual child and his previous psychosocial situation and on the characteristics of his new living conditions. It also remains to be proved that such catching up in developmental areas is maintained outside the educational environment. The studies cited above, which focus mainly on childhood and adolescence, provide no answers concerning those effects in adulthood.

Table 1 summarizes the findings of the most significant studies conducted over the last 30 years. These results will be looked at later: However, it is immediately clear that the situations observed are not as critical as many clinical or social publications would suggest.

\section{METHODS}

\section{Context of the follow-up study}

Oeuvre Grancher (OG) is a child care agency for foster families, originally set up in 1904 to protect children whose parents has contracted tuberculosis. It has since been transformed into a "specialized" foster care agency for children from families with serious psychosocial and psychiatric problems. Since 1970, the agency staff has been expanded to include social workers, psychiatrists, psychologists and therapists. A team was set up in 1988 to carry out this research project and included: (1) an institutional group consisting of a psychiatrist, a psychologist and a secretary; and (2) an external group consisting of researchers not affiliated with the institution.

\section{Selection of the Study Population}

The selection process was based on three specific criteria: The subjects had to

- have lived for at least five years in foster families (FF)

- have left care over five years earlier

- be at least 23 years old at the time of the study (5 years over the legal voting age, 18 years old in France).

Before 1967, children rarely stayed for long periods in an FF, although some were returned to care several times if their parents' health required it. Fifty-nine (59) subjects were selected from among the 2,843 files for children admitted between 1966 and 1978 . Four older siblings of the sibships (admitted between 1960 and 1964) who also met the requirements were subsequently added. The follow-up study therefore covered 63 adults who had left foster care between 1972 and 1984.

\section{Ethical considerations and Procedure}

A letter, accompanied by an invitation to participate, was sent to each person via INSERM (the research institute where the first author works). Some of these letters were forwarded by the foster families or siblings and some were signed by a member of the institution known to the young adult. The taped interviews were carried out by researchers (1990-92). Those interviewed were assured that their self-monitoring reports would remain anonymous and that the institution would only receive a global synthesis of the interviews.

\section{Data collection and Analysis}

Institutional data was initially filled out in the five OG foster care agencies before being systematically sorted and coded by two assistant researchers. Semi-structured interviews were then conducted, covering various topics including (1) current living conditions; (2) parental history and family links; (3) former life in care; and (4) criticisms of the child care system. Clinical data from the interviews was compared with that available in the institutional files (Coppel \& Dumaret, 1995 ). The information collected was also contrasted with the recollections of the foster families contacted. The data files analyzed were: (1) family situation at the time of admission; (2) foster care, duration of support (educational, individual or group therapy), scholastic achievement and job training, relationships with parents (number and regularity of contacts or visits) and type of discharge. The interview data was summarized in an overall social integration score, based on a scale ranging from $3(-)$ to $12(+)$ points (see Annex 1 ). Slightly more weight was accorded to the relationship dimension than to the occupational and health situation. It was useful in assessing the ability to establish relationships either with people in the family environment or with the foster family or both. 
Three risk factors for transmission of behavior problems were analyzed: (1) RF1, factors related to parental childhood or adolescence, including care experiences: no placement, one parent in care, both parents in care (0-2 points); (2) RF2, family and behavioral problems and/or psychiatric disorders of one or both parents (0-7 points); (3) RF3, factors related to pre-admission childhood experiences including the type of placement, neglect or abuse and their degree of severity ( $0-4$ points).

The data was analyzed using conventional tests, including comparisons of frequencies $\left(\mathrm{X}^{2}\right)$ and correlations between variables (Pearson's r). Simple and multiple regression analyses (ridge regression with lambda $=.100$, Beta coefficient $r$ ) were carried out with the overall integration score as the dependent variable to test the associated risk factors (Statistica for Windows, Release 4.0, Statsoft, 1993 ).

\section{RESULTS}

\section{Description of the study population \\ Home environment at time of admission}

(Table 2 ) The 63 young adults (33 males and 30 females) came from a total of 35 sibships. The families involved represented a total of 201 children -55 of whom where siblings also being raised by a foster family but not part of this study, and 86 other children, either under foster care elsewhere or living with their parents. In each case, it was the younger children who had been looked after by this institution. A large proportion had already had multiple admissions into care, sometimes lasting several years. Social worker reports gave various reasons for care in addition to parental disease (tuberculosis): maltreatment (5 victims of physical or sexual abuse), deprivation and parental deviance: alcoholism ( $49 \%$ of the fathers and $23 \%$ of the mothers), mental illness ( $20 \%$ of the mothers and $9 \%$ of the fathers) and asocial behavior (in twice as many fathers as mothers).

Several variables were correlated $(\mathrm{p}<.05)$ : families on welfare and social assistance which already had children in care $(\mathrm{r}=.35)$ and parents with behavioral or mental problems; maternal antecedents and the legal decision to remove children from the family (alcoholism: $r$ $=.25$; psychiatric problems: $\mathrm{r}=.50)$.

\section{Children in care}

(Table 3 ) The mean length of placement was 8 years and the mean age at discharge was 15 and 1/2. Fifty-two percent of the children had only one FF. Despite equivalent lengths of stay in care, boys experienced more changes than girls: $27 \%$ of the boys vs. $3 \%$ of the girls lived with more than two families $\left(\mathrm{X}^{2}=4.63, \mathrm{p}<.03\right)$. Educational and psychological assistance were extensive and correlated to the level of disturbance in the families ( $\mathrm{r}=.30, \mathrm{p}<.05)$. The duration of such therapeutic support was correlated to repeated admissions to care before OG $(\mathrm{r}=.31, \mathrm{p}<.05)$.

\section{Outcome at adulthood}

The main characteristics of the 45 adults interviewed are summarized in Table 4 . A quarter had a junior high school diploma, three had a high school diploma (baccalauréat) and one had a college degree (a masters in sociology). Forty-two percent had vocational diplomas and two-thirds of the men had completed their military service (the other third having been exempted).

\section{General situation of the 45 participants}

Those interviewed ranged in age from 23 to 39. Half of the couples had been living together for more than 7 years, although not always married. Twenty of the 36 individuals with a partner had always lived with that partner. Two-thirds of the adults were rearing their children. More men than women were living alone and childless $\left(X^{2}=11.64, p<.01\right)$. Three-quarters were employed and more than half were happy with their job. Only two of the interviewees were not living independently, with $29 \%$ owning their own home. A little over a quarter had kept up a relationship with the social workers they had known during their time in foster care. Most considered themselves to be in good health but $38 \%$ mentioned psychosomatic problems. One-third had experimented with drugs at one time or another. Ten mentioned problems of a social nature (run-ins with the law) shortly after leaving care, for a total of four minor offences and six arrests or court convictions (three in the criminal court: two for relatively minor offenses and one for murder).

\section{Social integration}

There were no outstanding differences between men and women, except that the women had a more developed network of social and family relationships and a higher proportion of men were employed. Five profiles were highlighted, based on the scale (mean score $=8$ points) (Annex 2 ):

- Profile 1: $35 \%$ of the participants with scores between 10 and 12 points $(n=16)$. They appeared well-integrated socially and all claimed to be in good health. All were living with a partner with the exception of one male (since married and now a father). Their social life was extremely varied and extended. All had friends they could court on in a crisis. 
- Profile 2: $27 \%$ of the participants with scores between 8 and 9 points $(n=12)$. They were relatively well-adapted socially, although relationships with family and friends were less diversified than for Profile 1. All had established their own family and those who did not yet have a child were intending to have one in the near future. Some complained of minor health problems.

- Profile 3: $9 \%$ of the interviewees with a score of 7 points $(n=4)$. They were well-integrated as a whole. Three had started families All were in relatively good health but complained of psychosomatic disorders. Only two were currently employed. All had friends and maintained relationships with their siblings but no longer kept in touch with their FFs.

- Profile 4: $20 \%$ of the participants with scores between 5 and 6 points $(n=9)$. Not fully integrated socially. Seven no longer had any contact with their FFs, no real social life and only maintained relationships with some siblings. Three had had either major or minor problems (psychologically fragile, occasional drug-taking). Some had received regular counseling by social workers. Some were no longer rearing their first child by a previous relationship. Their partner's family was not perceived as being very supportive.

- Profile 5: $9 \%$ of the participants with scores of between 3 and 4 points $(n=4)$. Poor social integration. None was self-sufficient: two had jobs in sheltered workshops, one man was living with his sister who was his guardian and another was in prison. Social relations were generally limited to FFs and social workers. None had established a family: one young woman had divorced after a two year marriage and was now living alone; one of the men was in the process of divorcing and was not raising his child.

\section{Family attachments}

The ex-care adults in this study had been confronted with two different upbringings in their childhood and adolescence. As adults (see Table 5 ), they generally opted to prioritize their relationships with one or other of the two families ( $<$.01): in other words, those who had regular contacts with their parent(s) had only very sporadic relationships with the FF $(n=13)$ and vice versa $(n=18)$. Only four kept in regular contact with both. Ten had very little contact with either.

These choices were linked to the age at which they left the FF and to family bonds before admission to care. Difficulties in child-parent bonding before entering care, in addition to a lack of parent-child relationships during care, are obvious issues that continued on into adulthood. A lack of an early family attachment is rarely reversible: children who had already been in care before admission to OG have less adult contact with their parents than children who had not experienced separation before admission to $\mathrm{OG}\left(\mathrm{X}^{2}=5.72, \mathrm{p}<.02\right)$.

\section{Correlation between deprivation in childhood, foster care and adult outcome}

Children experiencing learning difficulties before admission ( 2 or more years behind, in remedial classes) faced greater problems getting a diploma later on $\left(\mathrm{X}^{2}=7.23, \mathrm{p}<.01\right)$. The length of their stay in care impacted favorably on scholastic achievements: most of the young adults with diplomas benefited from long-term stays in an FF and left care after completing the mandatory number of school years. Table 6 highlights the correlation between the variables and the social integration score ( $\mathrm{r}$ Beta, ridge regression analysis). None of the adverse parental conditions alone had a significant impact on social integration in adulthood, with the exception of two variables: families on welfare before admission $(r=.340, \mathrm{p}<.02)$ and the presence of other sibs in care $(r=.301, \mathrm{p}<.05)$.

Foster care or separations in the preceding generation (RF1) were not risk factors for adult social integration. However, parental problems and deviance (RF2) and childhood problems (RF3) did have a statistically significant effect on social integration scores (p < $.005)$. This was also true for the age factor at the time of survey $(\mathrm{p}<.005)$. These three variables together accounted for $34 \%$ of the variance in the overall adult integration score $(\mathrm{r}=.583, \mathrm{p}<.001)$. After adjustment for age, both RF2 and RF3 remained significant $(\mathrm{p}=$ .022 and $p<.027)$. The forward stepwise regression analysis indicated that RF2 was the more predictive factor.

\section{Transmission of "childplacement" behaviors}

Intergenerational transmission of "child placement" behaviors, observed in the two former generations, was analyzed backwards and forwards in these families.

Retrospective data analysis (between the grandparents' generation and that of the parents): Placement would not appear to be accidental in these families; many of the grandparents had a personal history of foster care with their own children. The transmission rate was $51 \%$ for the 35 families studied and in 18 families at least one parent was an "ex-care" child. The tendency of both parents to pass on " placement behaviors" occurred in $23 \%$ of cases;: in eight families, both the mother and the father had themselves been separated from their families in childhood or adolescence.

Prospective analysis (on the 34 adults with children of their own [29 of the 45 interviewees and 5 of the 14 subjects who were not interviewed but for whom data was available]): In the case of three men and one woman, the oldest child was not living at home but was instead being raised by the other parent, ex-partner. The proportion of "newly composed families" did not differ from the general 
population. None of the 34 adults had a child in foster care. A single instance of a child being given up at birth for adoption by a minor was reported indirectly. When the woman in question (now married with several children) was interviewed, her overall score of 11 points indicated satisfactory integration in all the areas covered. Although this is in fact an instance of intergenerational transmission in the strictest sense of the term, it can nevertheless be said that transmission of child placement (in foster agencies) behaviors has virtually disappeared, whereas it had occurred in $43 \%$ of cases in the previous generation of these 34 parents.

\section{DISCUSSION}

This follow-up study on 63 subjects looked at environmental risk factors and the long term effects of foster care. All those involved has been in foster care for at least 5 years. Because of the pattern of repeated deprivation, this ex-care population was exposed to numerous risk factors. Seventy-one percent of the study population represented families of 4 or more children compared with $11 \%$ for France as a whole in 1975 (INSEE, 1993 ). They had an average of 5.7 children per mother compared with 2.7 for the same generation of lower class women (INED, 1979 ). Parental deviance was considerably more frequent than in the general population: alcoholism was 4 times more prevalent for fathers and 10 times for mothers; psychiatric disturbances were 4 times more prevalent in these families than in the general population (Choquet, Facy, Laurent and Davidson, 1982 ). As is often the case, the families had a large number of other children in care and were frequently on welfare (Dumaret, Duyme and Tomkiewicz, 1991 ).

The mean age for the group was 27.8 at time of follow-up. Outcome was systematically looked at from several complementary angles including the viewpoints of both the foster children as adults and that of the institution and their foster families. The high rate of participation - 45 individuals agreed to be interviewed (71\%) - reflects their desire to talk about their past. The information obtained for 14 other subjects raised the percentage to $94 \%$ of the study population. The strong ties between those working in the institution and some of the interviewees was probably also a factor in the high response rate.

\section{Young adults interviewed}

Strict comparisons with national norms were not possible for all the data collected (INSEE, 1990 , 20-39 age-group, all social classes confounded). The ex-foster care population from underprivileged environments had fewer general diplomas (67\% had none compared with $22 \%$ for the population as a whole - see Table 4 ) but more vocational and occupational training (42\% vs. 27\%). The proportions of unattached individuals, persons living with a partner and persons with children were the same, but the percentage of separated or divorced persons was higher than for the population as a whole. The occupational job figures for the ex-care population does not differ significantly from national norms.

The main socio-demographic and relationship characteristics of these young adults were comparable to those found in other studies (see Table 1 ). The majority were satisfied with their situations, despite feeling some degree of stigmatization. They felt they had managed to overcome numerous prejudices concerning their background. Overall, the portrait the interviewees painted of themselves was not fundamentally different from that of other same-age individuals from socially similar environments. An identical proportion maintained relationships with their original families (notably with their siblings) in addition to keeping in touch with their foster families (Festinger, 1983 ). Many were living with a partner and had children they were raising themselves. The proportion of men living along was higher than that of women, which is also borne out by other research results (SOS Children's Villages studies; Meier, 1965 ; Corbillon, Duyme, $1990)$.

However, the study showed - and this result is confirmed by other research findings - that it was after leaving care and when seeking employment that the main integration difficulties came up, often in everyday situations (financial problems, housing, etc.). It was generally at this time that they tended to get into trouble with the law and the police, essentially for minor problems (Ferguson, 1966 ; Triseliotis, 1980 ; Dumaret, 1982 ; Stein \& Carey, 1986 ; Raithel \& Wollensack, 1988 ). Our results need to be compared with the situation of young people from disadvantaged backgrounds. Nevertheless, it explains the steps taken by OG, which set up a special service for the young people leaving the institution without a sufficiently extensive social network after 1985.

Although their general health could be classified as good in this study, hospitalizations after leaving the foster family and psychosomatic problems were numerous. These figures have been borne out by other studies. Adults who claim to have experienced emotional problems during childhood are more likely to mention illness, accidents and other signs of distress as adults (Menahem \& Bantman, 1994 ). In Festinger's study (1983), a large number of ex-care adults complained more about psychosomatic problems than did other young adults. The author also stated that

"more of them had turned to mental health professionals for advice or help, ...perhaps they were more prone to label things as problems. Their past experience in foster care probably sensitized them to look for problems and made them more aware of resources for help and guidance". (p. 244). 
The age factor accounted for $22 \%$ of the variance in the overall integration score ( $\mathrm{p}<.001)$. After leaving foster care in the period 1972 -1975 , the older adults found themselves facing an economic situation that was undeniably better than that facing those who left between 1983-1984. The former experienced fewer periods of unemployment $(\mathrm{p}<.05)$ and their job histories were more stable. They had also had more time to develop a network of relationships. Consequently, the fact that the older persons in the study had the best profiles can be seen as a good omen for most of the younger subjects.

\section{Young adults not interviewed: Bias Analysis}

Eighteen adults could not be interviewed for the study. Up-to-date information was obtained for 14 of them, but the others were lost (see Table 7 ). At time of admission, there were no significant differences between the 45 participants and the 18 other adults in terms of family adversities. However, discharge occurred earlier for the non-participants. Data was collected from child care assistants, members of the foster care staff and siblings.

The 14 nonrespondents can be tentatively assigned a profile based on their social integration rating. Three were experiencing serious social and professional difficulties and had psychological or psychiatric problems (equivalent to profile 5, mean score 3.5 points). Three others had an unstable social integration level (equivalent to profile 4, mean score: 5.5 points) and three were relatively well-integrated, living with a partner, working and had at least two children (equivalent to profile 3, mean score: 7 points). The remaining five were quite well-integrated, since at least three of them were working and some occasionally got in touch with their FFs (equivalent to profile 2, mean score: 8 points).

\section{Social Integration of the 59 Ex-care Individuals}

The social integration of the 59 ex-care individuals for whom information was available can be summarized as follows (Table 8 ): 33 persons had a good social integration status (56\%), 7 had an average status (12\%), 12 remained only relatively well or partially integrated (20\%) and 7 were poorly integrated (12\%). These results are in line with those obtained by Bauer et al. (1993) on the assessment of the long-term support from the Child Welfare Services and the Agency for the Legal Protection of Youth.

As shown in Festinger's study (1983), age of admission to care and the number of FFs were not determining factors for later integration into society. Other variables such as family disorders or type of admission (placement ordered by a court or not) can also be correlated. The children with the most maladjusted behavior were often those who changed FF. However, it should be borne in mind that such changes do not represent a complete environmental change (usually the same foster care staff, same town). Cumulative adverse parental or child problems had a significant impact on social integration. Rutter \& Quinton (1984) also showed that:

"parental deviance had a significant association with adult personality disorder and a non-significant association with poor psychosocial functioning. Parental deviance put the child at risk not because of any direct inheritance but rather because it predisposed to adverse experiences that themselves constituted a serious risk factor" (p. 195).

These results are even more statistically significant as they apply to all 59 adults ( $r=.531, \mathrm{p}<.0001)$ : RF2 and RF3 accounted for $28 \%$ of the variance scores. Among the 19 young adults with poor integration scores, 11 had experienced various kinds of deprivation and family hardship: with the exception of one individual, they all had relatively severe mental health problems (half suffered from psychiatric disorders). The remaining eight had not been subjected to multiple risk factors: Only one had severe psychological problems and was not self-sufficient (Table 7 ). This data shows that severe emotional deprivation over prolonged periods is a contributing factor to the development of clinical disorders.

Our study's results showed a higher rate of intergenerational continuity of child placement behaviors when looking backwards than when looking forwards (Quinton, Rutter, Little, 1984 ). The chain of such behavior has been broken, thanks to changes in the environment, care continuity and backup support from the foster care staff. However, this positive outcome has still to be tested over time as a large majority of those interviewed have not yet finished establishing a family. Nevertheless, many of their own parents already had children in care at the same age. The individuals most at risk are those with low scores on the social integration scale. Even when the worst case scenario is adopted, the results are identical to those found by Festinger, comparable to the intergenerational transmission rate found by Corbillon et al. (1988, 1990) and below that obtained by Quinton \& Rutter (1984a , 1984b ).

The social integration scale found in this study would appear to be a good indicator of the general situation of those studied and is consistent with the study of their psychological functioning (Dumaret \& Coppel-Batsch, 1996 ). It is a discriminating index, both prospectively (the findings were confirmed for both low and high scores several months after the study) and retrospectively (multiple risk factors and low scores). 
The question of relationships with parents during foster care requires some additional qualification. Some of those in the study had been confronted by parental rejection. In certain cases, this already negative attitude was compounded by the fact that other siblings were accepted. Nine adults were in this category and five of them were experiencing difficulty as adults, despite benefiting from substantial care and backup support from the institution. This shows how difficult it is to protect a child from parental rejection and the associated cruelty and potentially harmful effects of later parent-child encounters.

Two-thirds of the young adults interviewed stated that the institution "had given them something"; most felt they had been helped. It provided them with a family life and initiated them into the personal relationships, rituals and structures that family life involves. The day-to-day duties and prohibitions in the foster family, even when they led to conflicts, seem to have contributed to creating a structuring framework, qualified as "protective" by some of those concerned: "If they hadn't made me behave, I would have become a delinquent. I'll be strict with my children too".

The satisfactory social integration and good general health of the majority of those interviewed can be linked to the stability of the care environment and the substantial backup support they received from OG. Many have learned to cope with adversity. Some of the young adults who arrived late in a foster family after numerous other placements still managed to achieve successful integration, along with some individuals from very psychologically and socially maladjusted families. However, the links between the past and the present remain complex. The problems encountered by some of the subjects must be correlated with multiple family deficiencies and substantial deprivation during childhood and adolescence. Inequalities among individuals were contained thanks to the stable and high quality foster care provided by the institution, but foster care staff can seldom fully compensate for all the adversities the children in their care have experienced.

\section{Ackowledgements:}

We would like to thank the entire staff of the institution for their contributions. Special thanks are extended to Professor Charles Bach, general secretary, Anne-Marie Thorin, head director and Catherine Sciamma, psychologist. We are grateful to Michel Duyme, CNRS senior researcher for helpful comments on this text.

\section{Annex 1}

- The first score (1-3 points) measured general health as defined by the WHO. Mental illness per se was not coded, as none of the subjects was in a psychiatric institution. The interviewee's assessment of his/her own health was taken into account (very satisfying, normal or average) in relation to specific symptoms. A distinction was made between hospitalizations and illnesses which had been diagnosed and treated (asthma, tuberculosis, mental disturbances, etc.) (score: 1 point) and vague psychosomatic problems: fatigue, backache, stomach problems, sleep disorders, etc. (2 points).

- The second score (0-3 points) assessed the professional situation and financial self-sufficiency of the subject. It looked at: (a) current employment (or previous employment for women now rearing children, in which case a point was given for a past job held for a fixed amount of time); (b) occupational stability and upgrading of work qualifications and (c) job continuity and any periods of unemployment in the past three years at least.

- The third score (0-2 points) reflected the participant's private and home life. This was defined by whether the person had had a current partner for at least one year (1 point) and/or had children living at home (1 point). A score of 2 points was given to those raising their own children, 1 point when the older children lived with a former partner and 0 points to single persons or divorcees without children.

- The fourth score (0-2 points) assessed social relations with his/her family, parents and/or siblings in addition to outsiders (friends, colleagues, etc.). Interpersonal relationships has to be regularly maintained (several annual encounters in addition to telephone calls), with at least one or two people to qualify for consideration.

- The fifth score (0-1 point) covered the relationships between the participant and the members of the foster family. Only regular contacts were counted.

- The sixth score (0-1 point) dealt with the participant's general psychological state. One point was attributed to persons receiving no backup support from social workers and who had no particular behavioral problems.

\section{Annex 2 : Social integration scores for the 45 participants}




\begin{tabular}{|c|c|c|c|c|c|c|c|c|}
\hline Age & Sex & Health & Work & Family & $\mathbf{F F}^{\prime} \mathbf{R}$ & S R & Ps $S$ & Score \\
\hline 26 & $\mathrm{M}$ & 1 & 1 & 0 & 1 & 0 & 0 & 3 \\
\hline 23 & $\mathrm{~F}$ & 1 & 0 & 0 & 1 & 1 & 0 & 3 \\
\hline 24 & M & 2 & 0 & 0 & 0 & 1 & 1 & 4 \\
\hline 25 & M & 2 & 0 & 0 & 1 & 1 & 0 & 4 \\
\hline 28 & $\mathrm{~F}$ & 3 & 2 & 0 & 0 & 0 & 0 & 5 \\
\hline 30 & $\mathrm{~F}$ & 3 & 0 & 2 & 0 & 0 & 1 & 6 \\
\hline 25 & M & 2 & 3 & 0 & 0 & 1 & 1 & 6 \\
\hline 28 & $\mathrm{~F}$ & 3 & 1 & 1 & 1 & 0 & 0 & 6 \\
\hline 27 & M & 2 & 1 & 0 & 1 & 1 & 1 & 6 \\
\hline 23 & $\mathrm{~F}$ & 2 & 0 & 2 & 0 & 1 & 1 & 6 \\
\hline 25 & $\mathrm{~F}$ & 2 & 0 & 2 & 0 & 1 & 1 & 6 \\
\hline 24 & M & 2 & 2 & 0 & 0 & 1 & 1 & 6 \\
\hline 27 & M & 3 & 0 & 0 & 0 & 2 & 1 & 6 \\
\hline 27 & M & 2 & 3 & 0 & 0 & 1 & 1 & 7 \\
\hline 30 & M & 1 & 1 & 2 & 0 & 2 & 1 & 7 \\
\hline 27 & M & 1 & 2 & 1 & 0 & 2 & 1 & 7 \\
\hline 25 & $\mathrm{~F}$ & 3 & 0 & 2 & 0 & 1 & 1 & 7 \\
\hline 25 & $\mathrm{~F}$ & 3 & 2 & 1 & 0 & 1 & 1 & 8 \\
\hline 25 & F & 2 & 0 & 2 & 1 & 2 & 1 & 8 \\
\hline 29 & $\mathrm{~F}$ & 2 & 1 & 2 & 0 & 2 & 1 & 8 \\
\hline 24 & M & 2 & 3 & 1 & 0 & 1 & 1 & 8 \\
\hline 32 & M & 1 & 3 & 1 & 1 & 1 & 1 & 8 \\
\hline 32 & $\mathrm{~F}$ & 2 & 2 & 1 & 1 & 1 & 1 & 8 \\
\hline 23 & $\mathrm{~F}$ & 1 & 2 & 2 & 1 & 2 & 1 & 9 \\
\hline 26 & M & 3 & 3 & 2 & 0 & 1 & 1 & 9 \\
\hline 30 & $\mathrm{~F}$ & 3 & 2 & 2 & 1 & 0 & 1 & 9 \\
\hline 33 & $\mathrm{~F}$ & 2 & 3 & 2 & 0 & 1 & 1 & 9 \\
\hline 26 & M & 3 & 3 & 1 & 1 & 0 & 1 & 9 \\
\hline 26 & M & 3 & 2 & 1 & 0 & 2 & 1 & 9 \\
\hline 36 & $\mathrm{~F}$ & 1 & 3 & 2 & 1 & 2 & 1 & 10 \\
\hline 27 & M & 2 & 3 & 1 & 1 & 2 & 1 & 10 \\
\hline 25 & M & 3 & 3 & 2 & 0 & 1 & 1 & 10 \\
\hline 24 & M & 3 & 3 & 1 & 1 & 1 & 1 & 10 \\
\hline 25 & M & 3 & 3 & 1 & 1 & 1 & 1 & 10 \\
\hline 25 & M & 3 & 3 & 0 & 1 & 2 & 1 & 10 \\
\hline 26 & $\mathrm{~F}$ & 3 & 3 & 1 & 0 & 2 & 1 & 10 \\
\hline 37 & M & 2 & 3 & 2 & 1 & 2 & 1 & 11 \\
\hline 35 & $\mathrm{~F}$ & 3 & 3 & 2 & 0 & 2 & 1 & 11 \\
\hline 28 & M & 3 & 3 & 2 & 0 & 2 & 1 & 11 \\
\hline 29 & $\mathrm{~F}$ & 3 & 3 & 2 & 1 & 1 & 1 & 11 \\
\hline 26 & $\mathrm{M}$ & 2 & 3 & 2 & 1 & 2 & 1 & 11 \\
\hline 33 & $\mathrm{M}$ & 2 & 3 & 2 & 1 & 2 & 1 & 11 \\
\hline
\end{tabular}




\begin{tabular}{|c|c|c|c|c|c|c|c|c|}
\hline 29 & $\mathrm{~F}$ & 3 & 3 & 2 & 0 & 2 & 1 & 11 \\
\hline 39 & $\mathrm{~F}$ & 3 & 3 & 2 & 1 & 2 & 1 & 12 \\
\hline 33 & $\mathrm{~F}$ & 3 & 3 & 2 & 1 & 2 & 1 & 12 \\
\hline
\end{tabular}

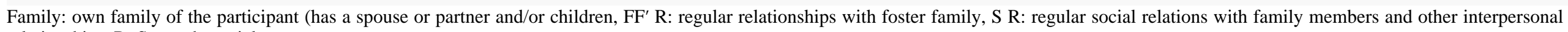
relationships. Ps S: psychosocial state. 


\section{References:}

- Ainsworth MD . 1962 ; Les Répercussions de la carence maternelle. Faits observés. Controverses dans le contexte de la stratégie des recherches . La carence de soins maternels, réévaluation de ses effets . 95 - 158 Genève Cahiers de l'OMS ;

- Aldgate J , Colton M, Gathe D, Health A . 1992 ; Educational attainment and stability in long term foster care . Children and Society . 6 : 91 - 103

- Bauer D, Dubechot P, Legros M . 1993 ; Le temps de l'établissement: des difficultés de l'adolescence aux insertions du jeune adulte . Paris CREDOC, Collection des Rapports

- Choquet M , Facy F, Laurent F , Davidson F . 1982 ; Les enfants à risque en âge pré-scolaire . Archives Françaises de Pédiatrie . 39 : 185 - 192

- Clarke AM , Clarke ADB . 1976 ; Early experience, myth and evidence . London Open Books ;

- Coppel M , Dumaret AC . Editor: Toulouse . 1995 ; Que sont-ils devenus? Les enfants accueillis à l'Oeuvre Grancher. Analyse d'un placement familial spécialisé . Erès

- Corbillon M , Assailly JP, Duyme M . 1988; L'Aide sociale à l'Enfance: descendance et devenir adulte . Population . 2 : 473 - 479

- Corbillon M , Assailly JP , Duyme M . 1990 ; L'enfant placé. De l'Assistance publique à l'Aide sociale à l'enfance . Paris Ministère de la Solidarité, de la Santé et de la Protection Sociale. ;

- Dobowitz H , Feigelman S, Zuravin S, Tepper V, Davidson N, Lichenstein R . 1992 ; The physical health of children in kinship care . American Journal of Diseases of Children . $146: 603-610$

- Dumaret A . 1982 ; Enquête sur les aînés de 18 ans et plus ayant été placés en Villages d'Enfants . Paris Association des Villages SOS d'Enfants de France (research report);

- Dumaret A . 1988a ; The SOS children's villages: school achievement of subjects reared in a permanent foster care. Part One . Early Child Development and Care . 34 : 217 226

- Dumaret A. 1988b ; The SOS children's villages: behaviour of children reared in a permanent foster care. Part Two . Early Child Development and Care . 34 : 267 - 277

- Dumaret A, Stewart J . 1989 ; Récupération des retards du développement psychologique après disparition des facteurs environnementaux néfastes . La Psychiatrie de l' Enfant, XXXII . $2: 593-615$

- Dumaret A, Duyme M, Tomkiewicz S . 1991 ; Enfants carencés placés après 4 ans en families adoptives avec un QI inférieur à la moyenne: étude des facteurs de vulnérabilit é. Neuropsychiatrie de l'Enfance et de l'Adolescence . $39: 265-283$

- Dumaret AC, Coppel-Batsch M . 1996 ; Evolution à l'âge adulte d'enfants placés en famille d'accueil . La Psychiatrie de l'Enfant, XXXIX . 2 : 613 - 671

- Duyme M, Dumaret A. Editor: Saucier JF, Houde L . 1990 ; La réversibilité des effets de carences socio-familiales précoces: une étude d'enfants adoptés tardivement . Pré vention psychosocial pour l'enfance et l'adolescence . 127 - 135 Montréal Presses de l'Université ;

- Essen J , Wedge P . 1982 ; Continuities in chilhood disadvantage . London Heinenmann Educational ;

- Fanshel D, Shinn EB . 1978 ; Children in foster care: a longitudinal investigation . New York Columbia University Press ;

- Ferguson T . 1966 ; Children in care and after . London Oxford University Press ;

- Festinger T . 1983 ; No one ever asked us. A postscript to foster care . New York Columbia University Press ;

- Goldstein J , Freud A, Solnit A . 1973 ; Beyond the interests of the child . New York The Free Press ;

- INED . 1979 ; VIIIème rapport sur la situation démographique de la France . Paris INED ;

- INSEE . 1990 ; Données sociales . Paris INSEE ;

- INSEE . 1993 ; Données sociales . Paris INSEE ;

- Klee L, Halfon N . 1987 ; Mental Health care for foster children in California . Child Abuse \& Neglect . 11 : 63 - 74

- Larsson G, Britt-Bohlin A, Stenbacka M . 1986 ; Prognosis of children admitted to institutional care during infancy . Child Abuse \& Neglect . 10 : 361 - 368

- Meier EG . 1965 ; Current circumstances of former foster children. Child Welfare . 44 : 196 - 206

- Menahmen G , Bantman P . 1994 ; Souvenirs d'enfance et maladies d'adultes. L'étrange vulnérabilité psychique des femmes à leurs problèmes d'enfance . Dialogue . 126 : 100 $-111$

- Pringle MLK, Bossio V . Editor: Pringle . 1971 ; Intellectual, emotional and social development of deprived children . Deprivation and education . 5 - 33 London Longsman \& National Children's Bureau ;

- Quinton D , Rutter M . 1984a ; Parents with children in care: I. Current circumstances and parenting . Journal of Child Psychology and Psychiatry . 25 : 211 - 229

- Quinton D , Rutter M . 1984b ; Parents with children in care: II. Intergenerational continuities . Journal of Child Psychology Psychiatry . 25 : 231 - 250

- Quinton D, Rutter M , Liddle . 1984 ; Institutional rearing, parenting difficulties and marital support . Psychological Medecine . 14 : 107 - 124

- Raithel M , Wollensack H . 1988 ; Les anciens des Villages d'Enfants SOS: que sont-ils devenus ? . Une étude catamnestique sur la maîtrise de la vie . Insbruck-Munich Institut de pédagogie sociale et Association allemande des Villages d'Enfants SOS, Édition française ;

- Rowe J , Cain H , Hundleby M , Keane A . 1984 ; Long term foster care . London British Agencies for Adoption and Fostering ;

- Rutter M , Madge N . 1976 ; Cycles of disadvantage; a review of research . London Heinemann ;

- Rutter M , Quinton D . 1984 ; Long-term follow-up of women institutionalized in childhood: Factors promoting good functioning in adult life . British Journal of Developmental Psychology . 2 : 191 - 204

- Schor E . 1982; The foster care system and health status of foster children . Pediatrics . 69: 521 - 28

- Soulé M, Noël J . 1971 ; Le grand renfermement des enfants dits cas sociaux . La Psychiatrie de l'Enfant . 14 : 577 - 620

- Statistica for Windows, Release 4.0, Statsoft, 1993.

- Stein M , Carey K . 1986 ; Leaving care . Oxford Basil Blackwell ;

- Swire MR , Kavaler F . 1977 ; The health status of foster children . Child Welfare, LVI . 635 - 653

- Triseliotis J . 1980 ; New development in foster care and adoption . London Routledge and Kegan Paul Ltd ;

- Wolkind S , Rutter M . 1973 ; Children who have been "in care" - an epidemiological study . Journal of Child Psychology and Psychiatry . 14 : 97 - 105 
Table 1

Adult outcome of ex-care children and adolescents (main studies)

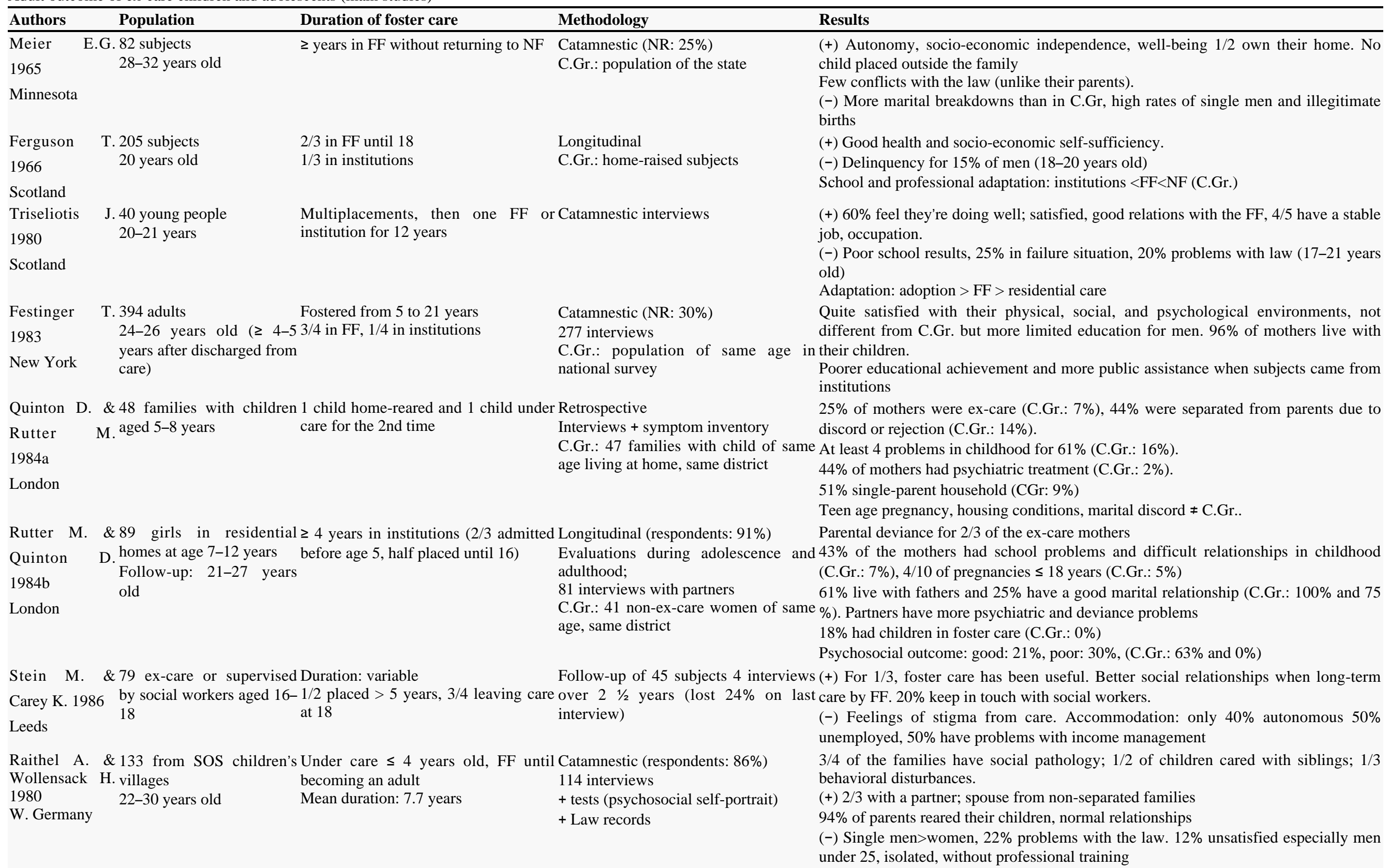




$\begin{array}{lll}\begin{array}{l}\text { Dumaret } \\ \text { A. } 374 \text { from SOS children's } 98 \text { sibships: placed } 1957-80 \\ \text { villages }\end{array} & \text { FF until becoming an adult } \\ \text { France } & 18-35 \text { years old } & \end{array}$

Catamnestic (respondents: $96 \%$ )

212 direct questionnaires

1/5 parental responsibility withdrawn from fathers; alcoholism (fathers: 39\%); menta health problems (mothers: $17 \%$ )

+148 indirect information from $\mathrm{FF},(+) 2 / 3$ have a diploma, $2 / 3$ have a job, $60 \%$ married or with partner, $1 / 2$ have siblings and social workers children, $90 \%$ live with them

(-) Difficulties at $18-25$ years, $10 \%$ have negative opinion about FF, single men>women

$(+)$ Stable foster families or adoption

Continuities in placement behavior and welfare assistance: $9.4 \%$ and $8.3 \%$

Corbillon M. et 563 adults

al. $1990>32$ and 39 yearsold

Duration: variable

Catamnestic

Adopted children and children under Follow-up on 2 generations

(-) Among those who have children in care: severe deprivation (court placements), placement)

regions

Bauer D. et al. 500 adults 2/3 under care for 12 years

19934 years after discharged

He de France from care

21-24 years old

Notes to table 1. FF: foster family, NF: natural family, NR: non-respondents, C.Gr.: control group

Transversal (respondents: $73 \%$ )

367 questionnaires and interviews

more single men, divorce, unemployement and early pregnancies $(2 / 3<21$ years old $)$.

Comparisons with general population $2 / 3$ no longer receive social help

of same age $\quad 27 \%$ still keep in touch with social workers

(-) Numerous failures when returning to family (1/3)

Table 2

Admission into care and parental history (35 families)

Placement for temporary care (26 children)

Placement ordered by the courts ( 37 children)

Tuberculosis

Alcoholism

Abuse and neglect

$26(4)$

$20(5)$

Family violence, parental conflicts

Families on social and welfare assistance

18

Behavioral and/or psychiatric disorders

( ) including both father and mother 
Table 3

Main characteristics of the 63 children in care

Characteristics $n$

Previous admissions into care

$\%$

Coming from :

family

residential institution

other foster family

Educational and therapeutic care

none

n

$<$ one year

$\geq$ one year

permanent

Length of foster care ( $\mathrm{m}=7.9$ years)

$$
\begin{aligned}
& <7 \text { years } \\
& 7-9 \text { years }
\end{aligned}
$$

$\geq 10$ years

Foster families

one

2-3

$\geq 4$

Relationship with parents

non existant or rare

irregular

regular

Age when discharged

$<15$ years old

$15-16$ years old

$\geq$ years old 
Table 4

Social and professional situation (45 interviews)

\begin{tabular}{|c|c|c|c|}
\hline Characteristics & Number & $\%$ & National norms (20-39 years) \\
\hline \multicolumn{4}{|l|}{ Age $(\mathrm{m}=27.8 \mathrm{y})$} \\
\hline 20-29 years & 33 & 74 & $50.2 \%$ \\
\hline 30-34 years & 12 & 27 & $49.8 \%$ \\
\hline \multicolumn{4}{|l|}{ Diplomas } \\
\hline Short (junior high school) & 12 & 26 & $18.5 \%$ \\
\hline Long (finished high school) & 3 & 7 & $32.4 \%$ \\
\hline No General Education diploma & 30 & 67 & $21.8 \%$ \\
\hline Technical or vocational school & 19 & 42 & $27.3 \%$ \\
\hline No technical diploma & 26 & 57 & \\
\hline Homeowners & 13 & 29 & $34 \%$ \\
\hline \multicolumn{4}{|l|}{ Marital status } \\
\hline$\overline{\text { Single }}$ & 23 & 51 & $47.9 \%$ \\
\hline Married & 18 & 40 & $47.9 \%$ \\
\hline Separated, divorced & 4 & 9 & $3.9 \%$ \\
\hline Widowed & - & - & $0.3 \%$ \\
\hline \multicolumn{4}{|l|}{ Family life } \\
\hline With spouse or partner & 36 & 80 & $82.3 \%$ \\
\hline Has children & 29 & 64 & $67.6 \%$ \\
\hline \multicolumn{4}{|l|}{ Occupation } \\
\hline Works & 33 & 73 & $81.0 \%$ \\
\hline \multicolumn{4}{|l|}{ socio-professional level: } \\
\hline Farmers & - & & $1.8 \%$ \\
\hline Craftmen, merchants & 5 & 11 & $3.7 \%$ \\
\hline Senior executive, professionals & - & - & $7.0 \%$ \\
\hline Middle class & 7 & 16 & $15.1 \%$ \\
\hline Employees, foremen & 11 & 24 & $24.7 \%$ \\
\hline Workers, service personnel & 17 & 38 & $26.2 \%$ \\
\hline Unemployed, without occupation & 5 & 11 & $21.5 \%$ \\
\hline \multicolumn{4}{|l|}{ Regular relationship with } \\
\hline Parents & 17 & 38 & \\
\hline Foster family & 23 & 51 & \\
\hline Spouse's family & 23 & 25 & \\
\hline \multicolumn{4}{|l|}{ Health } \\
\hline Good & 22 & 49 & \\
\hline Normal, average & 17 & 38 & \\
\hline Problems & 6 & 13 & \\
\hline
\end{tabular}


Table 5

Regular relationships in adulthood with parents and/or foster families

Relationships with parents

no
yes
total

$\mathrm{X}^{2}=7.03 \mathrm{p}<.01$ with foster families

Total

yes

no 10

18
4

22
17

45

Table 6

Risk factors and social integration in adulthood in the simple and multiple ridge regression analyses (lambda=.100)

\section{Variables}

R (beta)

RF1: ex-care parents

RF2: parental prob.

RF3: child neglect

Age at study

RF2 and RF3

Age, RF2, RF3

RF1: parental childhood and adolescence with placements

RF2: parental deviance (social and/or psychiatric disorders)

RF3: child's experience before OG admission (multiple admissions in care, type of neglect or abuse)
093

.417

.405

.467

.475

.582

$\mathbf{R}^{2}$

.008

.175

164

.218

.226

.340

7
5
8
6
40

ns

$<.005$

$<.01$

$<.001$

$<.005$

$<.001$ 
Table 7

Situation of the 14 subjects not interviewed

\begin{tabular}{cccccl}
\hline \multicolumn{2}{l}{ Sex } & Plct. RF2 & Age1 & F Age2 & Leaving care \\
\hline $\mathrm{F}$ & - & 1 & 1 & 17 & Family \\
$\mathrm{M}$ & + & 1 & 4 & 411 & Institution \\
$\mathrm{M}_{\mathrm{a}}$ & - & 1 & 6 & 212 & Parents \\
$\mathrm{M}_{\mathrm{a}}$ & - & 1 & 7 & 115 & Parents \\
$\mathrm{F}_{\mathrm{b}}$ & - & 3 & 3 & 29 & Parents \\
$\mathrm{F}_{\mathrm{b}}$ & $+\mathrm{T}$ & 3 & 6 & 111 & Parents \\
$\mathrm{F}$ & - & 3 & 5 & 110 & Parents \\
$\mathrm{M}$ & $+\mathrm{T}$ & 3 & 9 & 117 & Parents \\
$\mathrm{f}$ & $+\mathrm{T}$ & 0 & 8 & 215 & Parents \\
$\mathrm{M}$ & $+\mathrm{T}$ & 2 & 6 & 412 & Parents \\
& & & & & \\
$\mathrm{F}$ & - & 2 & 6 & 113 & Parents \\
$\mathrm{M}$ & $\mathrm{T}$ & 2 & 3 & 415 & Ran away from instit. \\
$\mathrm{M}$ & - & 3 & 9 & 118 & Parents \\
& & & & & MS \\
$\mathrm{F}$ & - & 5 & 6 & 312 & Parents \\
& & & & & \\
$\mathrm{F}_{\mathrm{c}}$ & + & 6 & 8 & 118 & Institution \\
$\mathrm{F}_{\mathrm{c}}$ & + & 6 & 10 & 215 & Ran away from instit. \\
$\mathrm{M}$ & + & 5 & 10 & 319 & MS \\
$\mathrm{M}$ & + & 7 & 2 & 318 & Ran away \\
$\mathrm{N}$ & + & & & &
\end{tabular}

1991

1992 Comments (evaluated scores)

Notes to Table 7.

$\mathrm{P}^{\circ} \quad$ Always had good relationship with his father

$\mathrm{P}^{\circ} \quad$ Maltreated by his mother during foster care; attended a psychology center

$\mathrm{P}^{\circ} \quad$ Went to young adult worker center

$\mathrm{P}$ These two sisters are still keep in touch with the FF (both scores: 8)

R1 Has a partner, works? Relationship with the whole family (score: 8)

R1 Minor delinquency after leaving care Single, regular job, good relationship with his interviewed brother (score: 8)

P Has a partner, a child, and a job (score: 8)

L Neglected by a FF, depression.

Has a spouse, child, regular job. No relationship with interviewed brothers (score: 7)

L Has a spouse, children? No relationship with interviewed sisters (score: 7)

R2 Minor delinquency after leaving care, behavior prob. Has a partner, children, rare contacts with interviewed brother (score 7)

$\mathrm{P}$ Delinquency, No relationship with interviewed siblings (score: 5.5)

R2 Deprivation, intellectually limited

Has 2 children, lives with a brother but has a regular job (score: 5.5 )

$\mathrm{P} \quad$ Child reared by grandmother (score:5.5)

L Psychiatric mother, serious deprivation

Drug user, alcoholism (score: 3.5 )

P Serious deprivation and maltreatment Delinquency (score: 3.5 )

L Deprivation, psychotic, Delinquency, lives on social fringes (score: 3.5 )

Age 1: admission into care, Age 2: when leaving foster family (FF),

a, b, c : siblings

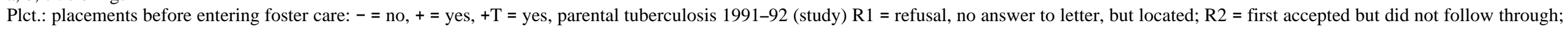

$\mathrm{L}=$ located only; $\mathrm{P}=$ lost, but additional information found; $\mathrm{P}^{\circ}=$ lost, no information since leaving care; Leaving care: MS = military service immediately.

Table 8

Adult social integration and cumulative risk factors $(n=59)$

\begin{tabular}{|c|c|c|c|c|}
\hline \multirow[t]{2}{*}{ Cumulative RF } & \multicolumn{3}{|c|}{ Social integration scores } & \multirow[t]{2}{*}{ Total $n$} \\
\hline & Poor $($ scores $<7$ ) & Average (score $=7$ ) & Good (scores $>7$ ) & \\
\hline$\leq 1 \mathrm{RF}$ & 8 & 5 & 26 & 39 \\
\hline$\geq 2 \mathrm{RF}$ & 11 & 2 & 7 & 20 \\
\hline Total (n) & 19 & 7 & 33 & 59 \\
\hline Total (\%) & 32.2 & 11.9 & 55.9 & $100 \%$ \\
\hline
\end{tabular}

$\mathrm{X}^{2}=7.34 \mathrm{p}=.025$ 